\title{
Directive 2004/27/EC of the European Parliament and of the Council of 31 March 2004
}

Amending Directive 2001/83/EC on the Community code relating to medicinal products for human use (Text with EEA relevance)

\section{THE EUROPEAN PARLIAMENT AND THE COUNCIL OF THE EURO- PEAN UNION,}

Having regard to the Treaty establishing the European Community, and in particular Article 95 thereof, Having regard to the proposal by the Commission (1), Having regard to the Opinion of the European Economic and Social Committee (2), After consulting the Committee of the Regions, Acting in accordance with the procedure laid down in Article 251 of the Treaty (3),

Whereas:

(1) Directive 2001/83/EC of the European Parliament and of the Council of 6 November 2001 on the Community code relating to medicinal products for human use (4), codified and consolidated in a single text the texts of Community legislation on medicinal products for human use, in the interests of clarity and rationalisation.

(2) The Community legislation so far adopted has made a major contribution to the achievement of the objective of the free and safe movement of medicinal products for human use and the elimination of obstacles to trade in such products. However, in the light of the experience acquired, it has become clear that new measures are necessary to eliminate the remaining obstacles to free movement.

(3) It is therefore necessary to align the national laws, regulations and administrative provisions which contain differences with regard to the basic principles in order to promote the operation of the internal market while realising a high level of human health protection.

(4) The main purpose of any regulation on the manufacture and distribution of medicinal products for human use should be to safeguard public health. However, this objective should be achieved by means which do not hinder the development of the pharmaceutical industry or trade in medicinal products in the Community.

(5) Article 71 of Council Regulation (EEC) No 2309/93 of 22 July 1993 laying down Community procedures for the authorisation and supervision of medicinal products for human and veterinary use and establishing a European Agency for the Evaluation of Medicinal Products (5) provided that, within six years of its entry into force, the Commission was required to publish a general report on the experience 
acquired as a result of the operation of the marketing authorisation procedures laid down in that Regulation and in other Community legal provisions.

(6) In the light of the Commission's report on the experience acquired, it has proved necessary to improve the operation of the marketing authorization procedures for medicinal products in the Community.

(7) Particularly as a result of scientific and technical progress, the definitions and scope of Directive 2001/83/EC should be clarified in order to achieve high standards for the quality, safety and efficacy of medicinal products for human use. In order to take account both of the emergence of new therapies and of the growing number of socalled 'borderline' products between the medicinal product sector and other sectors, the definition of 'medicinal product' should be modified so as to avoid any doubt as to the applicable legislation when a product, whilst fully falling within the definition of a medicinal product, may also fall within the definition of other regulated products. This definition should specify the type of action that the medicinal product may exert on physiological functions. This enumeration of actions will also make it possible to cover medicinal products such as gene therapy, radiopharmaceutical products as well as certain medicinal products for topical use. Also, in view of the characteristics of pharmaceutical legislation, provision should be made for such legislation to apply. With the same objective of clarifying situations, where a given product comes under the definition of a medicinal product but could also fall within the definition of other regulated products, it is necessary, in case of doubt and in order to ensure legal certainty, to state explicitly which provisions have to be complied with. Where a product comes clearly under the definition of other product categories, in particular food, food supplements, medical devices, biocides or cosmetics, this Directive should not apply. It is also appropriate to improve the consistency of the terminology of pharmaceutical legislation.

(8) Wherever it is proposed to change the scope of the centralised procedure, it should no longer be possible to opt for the mutual-recognition procedure or the decentralised procedure in respect of orphan medicinal products and medicinal products which contain new active substances and for which the therapeutic indication is the treatment of acquired immune deficiency syndrome, cancer, neurodegenerative disorder or diabetes. Four years after the date of entry into force of Regulation (EC) No 726/2004 (1), it should no longer be possible to opt for the mutual-recognition procedure or the decentralised procedure in respect of medicinal products which contain new active substances and for which the therapeutic indication is the treatment of auto-immune diseases and other immune dysfunctions and viral diseases.

(9) On the other hand, in the case of generic medicinal products of which the reference medicinal product has been granted a marketing authorisation under the centralised procedure, applicants seeking marketing authorisation should be able to choose either of the two procedures, on certain conditions. Similarly, the mutualrecognition or decentralised procedure should be available as an option for medicinal products which represent a therapeutic innovation or which are of benefit to society or to patients. 
(10) In order to increase availability of medicinal products, in particular on smaller markets, it should, in cases where an applicant does not apply for an authorisation for a medicinal product in the context of the mutual-recognition procedure in a given Member State, be possible for that Member State, for justified public health reasons, to authorise the placing on the market of the medicinal product.

(11) Evaluation of the operation of marketing authorization procedures has revealed the need to revise, in particular, the mutual-recognition procedure in order to improve the opportunities for cooperation between Member States. This cooperation process should be formalized by setting up a coordination group for this procedure and by defining its operation so as to settle disagreements within the framework of a revised decentralized procedure.

(12) With regard to referrals, the experience acquired reveals the need for an appropriate procedure, particularly in the case of referrals relating to an entire therapeutic class or to all medicinal products containing the same active substance.

(13) There is a need to provide for the ethical requirements of Directive 2001/20/EC of the European Parliament and the Council of 4 April 2001 on the approximation of the laws, regulations and administrative provisions of the Member States relating to the implementation of good clinical practice in the conduct of clinical trials on medicinal products for human use (2) to apply to all medicinal products authorised within the Community. In particular, with respect to clinical trials conducted outside the Community on medicinal products destined to be authorised within the Community, it should be verified, at the time of the evaluation of the application for authorisation, that these trials were conducted in accordance with the principles of good clinical practice and the ethical requirements equivalent to the provisions of that Directive.

(14) Since generic medicines account for a major part of the market in medicinal products, their access to the Community market should be facilitated in the light of the experience acquired. Furthermore, the period for protection of data relating to pre-clinical tests and clinical trials should be harmonised.

(15) Biological medicinal products similar to a reference medicinal product do not usually meet all the conditions to be considered as a generic medicinal product mainly due to manufacturing process characteristics, raw materials used, molecular characteristics and therapeutic modes of action. When a biological medicinal product does not meet all the conditions to be considered as a generic medicinal product, the results of appropriate tests should be provided in order to fulfil the requirements related to safety (pre-clinical tests) or to efficacy (clinical tests) or to both.

(16) The criteria of quality, safety and efficacy should enable the risk-benefit balance of all medicinal products to be assessed both when they are placed on the market and at any other time the competent authority deems this appropriate. In this connection, it is necessary to harmonise and adapt the criteria for refusal, suspension and revocation of marketing authorisations.

(17) A marketing authorisation should be renewed once five years after the granting of the marketing authorisation. Thereafter, the marketing authorisation should normally be of unlimited validity. Furthermore, any authorization not used for three 
consecutive years, that is to say one which has not led to the placing on the market of a medicinal product in the Member States concerned during that period, should be considered invalid, in order, in particular, to avoid the administrative burden of maintaining such authorisations. However, exemptions from this rule should be granted when these are justified on public health grounds.

(18) The environmental impact should be assessed and, on a case-by-case basis, specific arrangements to limit it should be envisaged. In any event this impact should not constitute a criterion for refusal of a marketing authorisation.

(19) The quality of medicinal products for human use manufactured or available in the Community should be guaranteed by requiring that the active substances used in their composition comply with the principles of good manufacturing practice in relation to those medicinal products. It has proved necessary to reinforce the Community provisions on inspections and to compile a Community register of the results of those inspections.

(20) Pharmacovigilance and, more generally, market surveillance and sanctions in the event of failure to comply with the provisions should be stepped up. In the field of pharmacovigilance, account should be taken of the facilities offered by new information technologies to improve exchanges between Member States.

(21) As part of the proper use of medicinal products, the rules on packaging should be adapted to take account of the experience acquired.

(22) The measures necessary for the implementation of this Directive should be adopted in accordance with Council Decision 1999/468/EC of 28 June 1999 laying down the procedures for the exercise of implementing powers conferred on the Commission (1).

(23) Directive 2001/83/EC should be amended accordingly,

\section{HAVE ADOPTED THIS DIRECTIVE:}

\section{Article 1}

Directive 2001/83/EC is hereby amended as follows:

1) Article 1 shall be amended as follows:

(a) point 1 shall be deleted;

(b) point 2 shall be replaced by the following:

'2. Medicinal product:

(a) Any substance or combination of substances presented as having properties for treating or preventing disease in human beings; or

(b) Any substance or combination of substances which may be used in or administered to human beings either with a view to restoring, correcting or modifying physiological functions by exerting a pharmacological, immunological or metabolic action, or to making a medical diagnosis.'

(c) point 5 shall be replaced by the following:

(1) See p. 1 of this Official Journal. (2) OJ L 121, 1.5.2001, p. 34. 
'5. Homeopathic medicinal product:

Any medicinal product prepared from substances called homeopathic stocks in accordance with a homeopathic manufacturing procedure described by the European Pharmacopoeia or, in the absence thereof, by the pharmacopoeias currently used officially in the Member States. A homeopathic medicinal product may contain a number of principles.';

(d) the Title of point 8 shall be replaced by 'Kit';

(e) the following point shall be inserted:

'18a Representative of the marketing authorisation holder:

The person, commonly known as local representative, designated by the marketing authorization holder to represent him in the Member State concerned'.

(f) point 20 shall be replaced by the following:

'20. Name of the medicinal product:

The name, which may be either an invented name not liable to confusion with the common name, or a common or scientific name accompanied by a trade mark or the name of the marketing authorization holder.';

(g) the heading of point 26 shall be replaced by the following:

(only concerns the Portuguese version);

(h) point 27 shall be replaced by the following:

'27. Agency:

The European Medicines Agency established by

Regulation (EC) No 726/2004 (*);

(i) point 28 shall be replaced by the following points:

'28. Risks related to use of the medicinal product:

- any risk relating to the quality, safety or efficacy of the medicinal product as regards patients' health or public health;

- any risk of undesirable effects on the environment;

28a. Risk-benefit balance:

An evaluation of the positive therapeutic effects of the medicinal product in relation to the risks as defined in point 28 , first indent.';

2) Article 2 shall be replaced by the following:

'Article 2

1. This Directive shall apply to medicinal products for human use intended to be placed on the market in Member States and either prepared industrially or manufactured by a method involving an industrial process.

2. In cases of doubt, where, taking into account all its characteristics, a product may fall within the definition of

(a) a "medicinal product" and within the definition of a product covered by other Community legislation the provisions of this Directive shall apply.

3. Notwithstanding paragraph 1 and Article 3(4), Title IV of this Directive shall apply to medicinal products intended only for export and to intermediate products.'; 
3) Article 3 shall be amended as follows:

(a) point 2 shall be replaced by the following:

'2. Any medicinal product which is prepared in a pharmacy in accordance with the prescriptions of a pharmacopoeia and is intended to be supplied directly to the patients served by the pharmacy in question (commonly known as the officinal formula).'

(b) point 3 shall be replaced by the following:

'3. Medicinal products intended for research and development trials, but without prejudice to the provisions of Directive 2001/20/EC of the European Parliament and of the Council of 4 April 2001 on the approximation of the laws, regulations and administrative provisions of the Member States relating to the implementation of good clinical practice in the conduct of clinical trials on medicinal products for human use (*).

4) Article 5 shall be replaced by the following:

'Article 5

1. A Member State may, in accordance with legislation in force and to fulfil special needs, exclude from the provisions of this Directive medicinal products supplied in response to a bona fide unsolicited order, formulated in accordance with the specifications of an authorized health-care professional and for use by an individual patient under his direct personal responsibility.

2. Member States may temporarily authorise the distribution of an unauthorised medicinal product in response to the suspected or confirmed spread of pathogenic agents, toxins, chemical agents or nuclear radiation any of which could cause harm.

3. Without prejudice to paragraph 1, Member States shall lay down provisions in order to ensure that marketing authorisation holders, manufacturers and health professionals are not subject to civil or administrative liability for any consequences resulting from the use of a medicinal product otherwise than for the authorized indications or from the use of an unauthorized medicinal product, when such use is recommended or required by a competent authority in response to the suspected or confirmed spread of pathogenic agents, toxins, chemical agents or nuclear radiation any of which could cause harm. Such provisions shall apply whether or not national or Community authorisation has been granted.

4. Liability for defective products, as provided for by Council Directive 85/374/EEC of 25 July 1985 on the approximation of the laws, regulations and administrative provisions of the Member States, concerning liability for defective products $(*)$, shall not be affected by paragraph 3 .

(*) OJ L 121, 1.5.2001, p. 34.';

(c) point 6 shall be replaced by the following:

'6. Whole blood, plasma or blood cells of human origin, except for plasma which is prepared by a method involving an industrial process.';

5) Article 6 shall be amended as follows: 
(a) in paragraph 1 , the following subparagraph shall be added:

'When a medicinal product has been granted an initial marketing authorisation in accordance with the first subparagraph, any additional strengths, pharmaceutical forms, administration routes, presentations, as well as any variations and extensions shall also be granted an authorisation in accordance with the first subparagraph or be included in the initial marketing authorisation. All these marketing authorisations shall be considered as belonging to the same global marketing authorisation, in particular for the purpose of the application of Article 10(1).';

(b) the following paragraph shall be inserted:

' $1 \mathrm{a}$ The marketing authorisation holder shall be responsible for marketing the medicinal product. The designation of a representative shall not relieve the marketing authorisation holder of his legal responsibility.';

(c) in paragraph 2, 'radionuclide kits' shall be replaced by 'kits';

6) in Article 7, 'radionuclide kits' shall be replaced by 'kits';

7) Article 8(3) shall be amended as follows:

(a) points (b) and (c) shall be replaced by the following:

(b) Name of the medicinal product.

(c) Qualitative and quantitative particulars of all the constituents of the medicinal product, including the reference to its international non-proprietary name (INN) recommended by the WHO, where an INN for the medicinal product exists, or a reference to the relevant chemical name;';

(b) the following point shall be inserted:

'(ca) Evaluation of the potential environmental risks posed by the medicinal product. This impact shall be assessed and, on a case-by-case basis, specific arrangements to limit it shall be envisaged.';

(c) points (g), (h), (i) and (j) shall be replaced by the following points:

' $(\mathrm{g})$ Reasons for any precautionary and safety measures to be taken for the storage of the medicinal product, its administration to patients and for the disposal of waste products, together with an indication of potential risks presented by the medicinal product for the environment.

(h) Description of the control methods employed by the manufacturer.

(i) Results of:

- pharmaceutical (physico-chemical, biological or microbiological) tests,

- pre-clinical (toxicological and pharmacological) tests,

- clinical trials.

(ia) A detailed description of the pharmacovigilance and, where appropriate, of the risk-management system which the applicant will introduce.

(ib) A statement to the effect that clinical trials carried out outside the European Union meet the ethical requirements of Directive 2001/20/EC.

(*) OJ L 210, 7.8.1985, p. 29. Directive as last amended by Directive 1999/34/EC of the European Parliament and of the Council (OJ L 141, 4.6.1999, p. 20).'; 30.4.2004 EN Official Journal of the European Union L 136/37 
(j) A summary, in accordance with Article 11, of the product characteristics, a mock-up of the outer packaging, containing the details provided for in Article 54, and of the immediate packaging of the medicinal product, containing the details provided for in Article 55, together with a package leaflet in accordance with Article 59.';

(d) the following points shall be added:

'(m) A copy of any designation of the medicinal product as an orphan medicinal product under Regulation (EC) No 141/2000 of the European Parliament and of the Council of 16 December 1999 on orphan medicinal products (*), accompanied by a copy of the relevant Agency opinion.

(n) Proof that the applicant has the services of a qualified person responsible for pharmacovigilance and has the necessary means for the notification of any adverse reaction suspected of occurring either in the Community or in a third country.

(e) the following subparagraph shall be added:

'The documents and information concerning the results of the pharmaceutical and pre-clinical tests and the clinical trials referred to in point (i) of the first subparagraph shall be accompanied by detailed summaries in accordance with Article 12.';

8) Article 10 shall be replaced by the following:

'Article 10

1. By way of derogation from Article 8(3)(i), and without prejudice to the law relating to the protection of industrial and commercial property, the applicant shall not be required to provide the results of pre-clinical tests and of clinical trials if he can demonstrate that the medicinal product is a generic of a reference medicinal product which is or has been authorised under Article 6 for not less than eight years in a Member State or in the Community. A generic medicinal product authorised pursuant to this provision shall not be placed on the market until ten years have elapsed from the initial authorisation of the reference product. The first subparagraph shall also apply if the reference medicinal product was not authorised in the Member State in which the application for the generic medicinal product is submitted. In this case, the applicant shall indicate in the application form the name of the Member State in which the reference medicinal product is or has been authorised. At the request of the competent authority of the Member State in which the application is submitted, the competent authority of the other Member State shall transmit within a period of one month, a confirmation that the reference medicinal product is or has been authorised together with the full composition of the reference product and if necessary other relevant documentation. The ten-year period referred to in the second subparagraph shall be extended to a maximum of eleven years if, during the first eight years of those ten years, the marketing authorisation holder obtains an authorisation for one or more new therapeutic indications which, during the scientific evaluation prior to their authorisation, are held to bring a significant clinical benefit in comparison with existing therapies.

2. For the purposes of this Article:

(*) OJ L 18, 22.1.2000, p. 1.'; 
(a) "reference medicinal product" shall mean a medicinal product authorised under Article 6, in accordance with the provisions of Article 8;

(b) "generic medicinal product" shall mean a medicinal product which has the same qualitative and quantitative composition in active substances and the same pharmaceutical form as the reference medicinal product, and whose bioequivalence with the reference medicinal product has been demonstrated by appropriate bioavailability studies. The different salts, esters, ethers, isomers, mixtures of isomers, complexes or derivatives of an active substance shall be considered to be the same active substance, unless they differ significantly in properties with regard to safety and/or efficacy. In such cases, additional information providing proof of the safety and/or efficacy of the various salts, esters or derivatives of an authorised active substance must be supplied by the applicant. The various immediate-release oral pharmaceutical forms shall be considered to be one and the same pharmaceutical form. Bioavailability studies need not be required of the applicant if he can demonstrate that the generic medicinal product meets the relevant criteria as defined in the appropriate detailed guidelines.

3. In cases where the medicinal product does not fall within the definition of a generic medicinal product as provided in paragraph 2(b) or where the bioequivalence cannot be demonstrated through bioavailability studies or in case of changes in the active substance(s), therapeutic indications, strength, pharmaceutical form or route of administration, vis-à-vis the reference medicinal product, the results of the appropriate pre-clinical tests or clinical trials shall be provided.

4. Where a biological medicinal product which is similar to a reference biological product does not meet the conditions in the definition of generic medicinal products, owing to, in particular, differences relating to raw materials or differences in manufacturing processes of the biological medicinal product and the reference biological medicinal product, the results of appropriate pre-clinical tests or clinical trials relating to these conditions must be provided. The type and quantity of supplementary data to be provided must comply with the relevant criteria stated in Annex I and the related detailed guidelines. The results of other tests and trials from the reference medicinal product's dossier shall not be provided.

5. In addition to the provisions laid down in paragraph 1, where an application is made for a new indication for a well-established substance, a non-cumulative period of one year of data exclusivity shall be granted, provided that significant pre-clinical or clinical studies were carried out in relation to the new indication.

6. Conducting the necessary studies and trials with a view to the application of paragraphs 1,2, 3 and 4 and the consequential practical requirements shall not be regarded as contrary to patent rights or to supplementary protection certificates for medicinal products.';

9) the following Articles shall be inserted:

'Article 10a 
By way of derogation from Article 8(3)(i), and without prejudice to the law relating to the protection of industrial and commercial property, the applicant shall not be required to provide the results of pre-clinical tests or clinical trials if he can demonstrate that the active substances of the medicinal product have been in well established medicinal use within the Community for at least ten years, with recognised efficacy and an acceptable level of safety in terms of the conditions set out in Annex I. In that event, the test and trial results shall be replaced by appropriate scientific literature.

\section{Article $10 b$}

In the case of medicinal products containing active substances used in the composition of authorised medicinal products but not hitherto used in combination for therapeutic purposes, the results of new pre-clinical tests or new clinical trials relating to that combination shall be provided in accordance with Article 8(3)(i), but it shall not be necessary to provide scientific references relating to each individual active substance.

Article 10c

Following the granting of a marketing authorisation, the authorisation holder may allow use to be made of the pharmaceutical, pre-clinical and clinical documentation contained in the file on the medicinal product, with a view to examining subsequent applications relating to other medicinal products possessing the same qualitative and quantitative composition in terms of active substances and the same pharmaceutical form.'; 10) Article 11 shall be replaced by the following:

'Article 11

The summary of the product characteristics shall contain, in the order indicated below, the following information:

1. name of the medicinal product followed by the strength and the pharmaceutical form.

2. qualitative and quantitative composition in terms of the active substances and constituents of the excipient, knowledge of which is essential for proper administration of the medicinal product. The usual common name or chemical description shall be used.

3. pharmaceutical form.

4. clinical particulars:

4.1. therapeutic indications,

4.2. posology and method of administration for adults and, where necessary for children,

4.3. contra-indications,

4.4. special warnings and precautions for use and, in the case of immunological medicinal products, any special precautions to be taken by persons handling such products and administering them to patients, together with any precautions to be taken by the patient,

4.5. interaction with other medicinal products and other forms of interactions,

4.6. use during pregnancy and lactation, 
4.7. effects on ability to drive and to use machines,

4.8. undesirable effects,

4.9. overdose (symptoms, emergency procedures, antidotes).

5. pharmacological properties:

5.1. pharmacodynamic properties,

5.2. pharmacokinetic properties,

5.3. preclinical safety data.

6. pharmaceutical particulars:

6.1. list of excipients,

6.2. major incompatibilities,

6.3. shelf life, when necessary after reconstitution of the medicinal product or when the immediate packaging is opened for the first time,

6.4. special precautions for storage,

6.5. nature and contents of container,

6.6. special precautions for disposal of a used medicinal product or waste materials derived from such medicinal product, if appropriate.

7. marketing authorisation holder.

8. marketing authorisation number(s).

9. date of the first authorisation or renewal of the authorisation.

10. date of revision of the text.

11. for radiopharmaceuticals, full details of internal radiation dosimetry.

12. for radiopharmaceuticals, additional detailed instructions for extemporaneous preparation and quality control of such preparation and, where appropriate, maximum storage time during which any intermediate preparation such as an eluate or the readyto- use pharmaceutical will conform with its specifications. L 136/40 EN Official Journal of the European Union 30.4.2004 For authorisations under Article 10 , those parts of the summary of product characteristics of the reference medicinal product referring to indications or dosage forms which were still covered by patent law at the time when a generic medicine was marketed need not be included.';

11) Article 12 shall be replaced by the following:

'Article 12

1. The applicant shall ensure that, before the detailed summaries referred to in the last subparagraph of Article 8(3) are submitted to the competent authorities, they have been drawn up and signed by experts with the necessary technical or professional qualifications, which shall be set out in a brief curriculum vitae.

2. Persons having the technical and professional qualifications referred to in paragraph 1 shall justify any use made of scientific literature under Article 10a in accordance with the conditions set out in Annex I.

3. The detailed summaries shall form part of the file which the applicant submits to the competent authorities.'; 12) Article 13 shall be replaced by the following:

'Article 13

1. Member States shall ensure that homeopathic medicinal products manufactured and placed on the market within the Community are registered or authorised in 
accordance with Articles 14, 15 and 16, except where such medicinal products are covered by a registration or authorisation granted in accordance with national legislation on or before 31 December 1993. In case of registrations, Article 28 and Article 29(1) to (3) shall apply.

2. Member States shall establish a special simplified registration procedure for the homeopathic medicinal products referred to in Article 14.'; 13) Article 14 shall be amended as follows:

(a) in paragraph 1, the following second subparagraph shall be inserted: 'If new scientific evidence so warrants, the Commission may amend the third indent of the first subparagraph by the procedure referred to in Article 121(2).';

(b) paragraph 3 shall be deleted;

14) Article 15 shall be amended as follows:

(a) the second indent shall be replaced by the following:

"- dossier describing how the homeopathic stock or stocks is/are obtained and controlled, and justifying its/their homeopathic use, on the basis of an adequate bibliography,';

(b) the sixth indent shall be replaced by the following:

'- one or more mock-ups of the outer packaging and the immediate packaging of the medicinal products to be registered,';

15) Article 16 shall be amended as follows:

(a) in paragraph 1, 'Articles 8, 10 and 11' shall be replaced by 'Articles 8, 10, 10a, $10 \mathrm{~b}, 10 \mathrm{c}$ and 11 '.

(b) in paragraph 2, 'toxicological and pharmacological tests' shall be replaced by 'pre-clinical tests';

16) Articles 17 and 18 shall be replaced by the following:

'Article 17

1. Member States shall take all appropriate measures to ensure that the procedure for granting a marketing authorisation for medicinal products is completed within a maximum of 210 days after the submission of a valid application. Applications for marketing authorisations in two or more Member States in respect of the same medicinal product shall be submitted in accordance with Articles 27 to 39.

2. Where a Member State notes that another marketing authorisation application for the same medicinal product is being examined in another Member State, the Member State concerned shall decline to assess the application and shall advise the applicant that Articles 27 to 39 apply.

Article 18

Where a Member State is informed in accordance with Article 8(3)(1) that another Member State has authorised a medicinal product which is the subject of a marketing authorisation application in the Member State concerned, it shall reject the application unless it was submitted in compliance with Articles 27 to 39.';

30.4.2004 EN Official Journal of the European Union L 136/41 17) Article 19 shall be amended as follows: 
(a) in the introductory sentence, 'Articles 8 and 10(1)' shall be replaced by 'Articles $8,10,10 \mathrm{a}, 10 \mathrm{~b}$ and 10c';

(b) in point 1, 'Articles 8 and 10(1)' shall be replaced by 'Articles 8, 10, 10a, 10b and 10c';

(c) in point 2, 'a State laboratory or a laboratory designated for that purpose' shall be replaced by 'an Official Medicines Control Laboratory or a laboratory that a Member State has designated for that purpose';

(d) in point 3, 'Articles 8(3) and 10(1)' shall be replaced by 'Articles 8(3), 10, 10a, $10 \mathrm{~b}$ and 10c';

18 ) in point (b) of Article 20, 'in exceptional and justifiable cases' shall be replaced by 'in justifiable cases';

19) in Article 21, paragraphs 3 and 4 shall be replaced by the following:

'3. The competent authorities shall make publicly available without delay the marketing authorisation together with the summary of the product characteristics for each medicinal product which they have authorised.

4. The competent authorities shall draw up an assessment report and comments on the file as regards the results of the pharmaceutical and pre-clinical tests and the clinical trials of the medicinal product concerned. The assessment report shall be updated whenever new information becomes available which is of importance for the evaluation of the quality, safety or efficacy of the medicinal product concerned. The competent authorities shall make publicly accessible without delay the assessment report, together with the reasons for their opinion, after deletion of any information of a commercially confidential nature. The justification shall be provided separately for each indication applied for.';

20) Article 22 shall be replaced by the following:

'Article 22

In exceptional circumstances and following consultation with the applicant, the authorisation may be granted subject to a requirement for the applicant to meet certain conditions, in particular concerning the safety of the medicinal product, notification to the competent authorities of any incident relating to its use, and action to be taken. This authorisation may be granted only for objective, verifiable reasons and must be based on one of the grounds set out in Annex I. Continuation of the authorisation shall be linked to the annual reassessment of these conditions. The list of these conditions shall be made publicly accessible without delay, together with deadlines and dates of fulfilment.';

21) in Article 23, the following paragraphs shall be added: 'The authorisation holder shall forthwith supply to the competent authority any new information which might entail the amendment of the particulars or documents referred to in Articles $8(3), 10,10 \mathrm{a}, 10 \mathrm{~b}$ and 11 , or 32(5), or Annex I.

In particular, he shall forthwith inform the competent authority of any prohibition or restriction imposed by the competent authorities of any country in which the medicinal product for human use is marketed and of any other new information which might influence the evaluation of the benefits and risks of the medicinal product for 
human use concerned. In order that the risk-benefit balance may be continuously assessed, the competent authority may at any time ask the holder of the marketing authorisation to forward data demonstrating that the risk-benefit balance remains favourable.';

22) the following Article shall be inserted:

'Article $23 a$

After a marketing authorisation has been granted, the holder of the authorisation shall inform the competent authority of the authorising Member State of the date of actual marketing of the medicinal product for human use in that Member State, taking into account the various presentations authorised. The holder shall also notify the competent authority if the product ceases to be placed on the market of the Member State, either temporarily or permanently. Such notification shall, otherwise than in exceptional circumstances, be made no less than 2 months before the interruption in the placing on the market of the product. Upon request by the competent authority, particularly in the context of pharmacovigilance, the marketing authorisation holder shall provide the competent authority with all data relating to the volume of sales of the medicinal product, and any data in his possession relating to the volume of prescriptions.'

L 136/42 EN Official Journal of the European Union 30.4.2004 23) Article 24 shall be replaced by the following:

'Article 24

1. Without prejudice to paragraphs 4 and 5 , a marketing authorisation shall be valid for five years.

2. The marketing authorisation may be renewed after five years on the basis of a re-evaluation of the risk-benefit balance by the competent authority of the authorising Member State. To this end, the marketing authorisation holder shall provide the competent authority with a consolidated version of the file in respect of quality, safety and efficacy, including all variations introduced since the marketing authorisation was granted, at least six months before the marketing authorisation ceases to be valid in accordance with paragraph 1 .

3. Once renewed, the marketing authorisation shall be valid for an unlimited period, unless the competent authority decides, on justified grounds relating to pharmacovigilance, to proceed with one additional five-year renewal in accordance with paragraph 2.

4. Any authorisation which within three years of its granting is not followed by the actual placing on the market of the authorised product in the authorising Member State shall cease to be valid.

5. When an authorised product previously placed on the market in the authorising Member State is no longer actually present on the market for a period of three consecutive years, the authorisation for that product shall cease to be valid.

6. The competent authority may, in exceptional circumstances and on public health grounds grant exemptions from paragraphs 4 and 5. Such exemptions must be duly justified.'; 
24) Article 26 shall be replaced by the following:

'Article 26

1. The marketing authorisation shall be refused if, after verification of the particulars and documents listed in Articles 8, 10,10a, 10b and 10c, it is clear that:

(a) the risk-benefit balance is not considered to be favourable; or

(b) its therapeutic efficacy is insufficiently substantiated by the applicant; or

(c) its qualitative and quantitative composition is not as declared.

2. Authorisation shall likewise be refused if any particulars or documents submitted in support of the application do not comply with Articles 8,10,10a, 10b and 10c.

3. The applicant or the holder of a marketing authorisation shall be responsible for the accuracy of the documents and the data submitted.';

25) the heading of Chapter 4 of Title III shall be replaced by the following:

\section{'CHAPTER 4}

\section{Mutual recognition procedure and decentralised}

procedure';

26) Articles 27 to 32 shall be replaced by the following:

'Article 27

1. A coordination group shall be set up for the examination of any question relating to marketing authorisation of a medicinal product in two or more Member States in accordance with the procedures laid down in this Chapter. The Agency shall provide the secretariat of this coordination group.

2. The coordination group shall be composed of one representative per Member State appointed for a renewable period of three years. Members of the coordination group may arrange to be accompanied by experts.

3. The coordination group shall draw up its own Rules of Procedure, which shall enter into force after a favourable opinion has been given by the Commission. These Rules of Procedure shall be made public.

Article 28

1. With a view to the granting of a marketing authorisation for a medicinal product in more than one Member State, an applicant shall submit an application based on an identical dossier in these Member States. The dossier shall contain the information and documents referred to in Articles 8, 10, 10a, 10b, 10c and 11. The documents submitted shall include a list of Member States concerned by the application. The applicant shall request one Member State to act as "reference Member State" and to prepare an assessment report on the medicinal product in accordance with paragraphs 2 or 3. 30.4.2004 EN Official Journal of the European Union L 136/43

2. Where the medicinal product has already received a marketing authorisation at the time of application, the concerned Member States shall recognise the marketing authorisation granted by the reference Member State. To this end, the marketing authorisation holder shall request the reference Member State either to prepare an assessment report on the medicinal product or, if necessary, to update any existing assessment report. The reference Member State shall prepare or update the assessment report within 90 days of receipt of a valid application. The assessment report together 
with the approved summary of product characteristics, labelling and package leaflet shall be sent to the concerned Member States and to the applicant.

3. In cases where the medicinal product has not received a marketing authorisation at the time of application, the applicant shall request the reference Member State to prepare a draft assessment report, a draft summary of product characteristics and a draft of the labelling and package leaflet. The reference Member State shall prepare these draft documents within 120 days after receipt of a valid application and shall send them to the concerned Member States and to the applicant.

4. Within 90 days of receipt of the documents referred to in paragraphs 2 and 3, the Member States concerned shall approve the assessment report, the summary of product characteristics and the labelling and package leaflet and shall inform the reference Member State accordingly. The reference Member State shall record the agreement of all parties, close the procedure and inform the applicant accordingly.

5. Each Member State in which an application has been submitted in accordance with paragraph 1 shall adopt a decision in conformity with the approved assessment report, the summary of product characteristics and the labelling and package leaflet as approved, within 30 days after acknowledgement of the agreement.

\section{Article 29}

1. If, within the period laid down in Article 28(4), a Member State cannot approve the assessment report, the summary of product characteristics, the labelling and the package leaflet on the grounds of potential serious risk to public health, it shall give a detailed exposition of the reasons for its position to the reference Member State, to the other Member States concerned and to the applicant. The points of disagreement shall be forthwith referred to the coordination group.

2. Guidelines to be adopted by the Commission shall define a potential serious risk to public health.

3. Within the coordination group, all Member States referred to in paragraph 1 shall use their best endeavours to reach agreement on the action to be taken. They shall allow the applicant the opportunity to make his point of view known orally or in writing. If, within 60 days of the communication of the points of disagreement, the Member States reach an agreement, the reference Member State shall record the agreement, close the procedure and inform the applicant accordingly. Article 28(5) shall apply.

4. If the Member States fail to reach an agreement within the 60-day period laid down in paragraph 3, the Agency shall be immediately informed, with a view to the application of the procedure under Articles 32, 33 and 34. The Agency shall be provided with a detailed statement of the matters on which the Member States have been unable to reach agreement and the reasons for their disagreement. A copy shall be forwarded to the applicant.

5. As soon as the applicant is informed that the matter has been referred to the Agency, he shall forthwith forward to the Agency a copy of the information and documents referred to in the first subparagraph of Article 28(1). 
6. In the circumstances referred to in paragraph 4, Member States that have approved the assessment report, the draft summary of product characteristics and the labelling and package leaflet of the reference Member State may, at the request of the applicant, authorise the medicinal product without waiting for the outcome of the procedure laid down in Article 32. In that event, the authorisation granted shall be without prejudice to the outcome of that procedure.

\section{Article 30}

1. If two or more applications submitted in accordance with Articles 8, 10, $10 \mathrm{a}, 10 \mathrm{~b}, 10 \mathrm{c}$ and 11 have been made for marketing authorisation for a particular medicinal product, and if Member States have adopted divergent decisions concerning the authorisation of the medicinal product or its suspension or revocation, a Member State, the Commission or the applicant or the marketing authorisation holder may refer the matter to the Committee for Medicinal Products for Human Use, hereinafter referred to as "the Committee", for the application of the procedure laid down in Articles 32, 33 and 34.

2. In order to promote harmonisation of authorisations for medicinal products authorised in the Community, Member States shall, each year, forward to the coordination group a list of medicinal products for which a harmonised summary of product characteristics should be drawn up. The coordination group shall lay down a list taking into account the proposals from all Member States and shall forward this list to the Commission. L 136/44 EN Official Journal of the European Union 30.4.2004 The Commission or a Member State, in agreement with the Agency and taking into account the views of interested parties, may refer these products to the Committee in accordance with paragraph 1.

\section{Article 31}

1. The Member States or the Commission or the applicant or the marketing authorisation holder shall, in specific cases where the interests of the Community are involved, refer the matter to the Committee for application of the procedure laid down in Articles 32, 33 and 34 before any decision is reached on a request for a marketing authorisation or on the suspension or revocation of an authorisation, or on any other variation to the terms of a marketing authorisation which appears necessary, in particular to take account of the information collected in accordance with Title IX. The Member State concerned or the Commission shall clearly identify the question which is referred to the Committee for consideration and shall inform the applicant or the marketing authorisation holder. The Member States and the applicant or the marketing authorisation holder shall supply the Committee with all available information relating to the matter in question.

2. Where the referral to the Committee concerns a range of medicinal products or a therapeutic class, the Agency may limit the procedure to certain specific parts of the authorisation. In that event, Article 35 shall apply to those medicinal products only if they were covered by the authorisation procedures referred to in this Chapter.

Article 32 
1. When reference is made to the procedure laid down in this Article, the Committee shall consider the matter concerned and shall issue a reasoned opinion within 60 days of the date on which the matter was referred to it. However, in cases submitted to the Committee in accordance with Articles 30 and 31, this period may be extended by the Committee for a further period of up to 90 days, taking into account the views of the applicants or the marketing authorisation holders concerned. In an emergency, and on a proposal from its Chairman, the Committee may agree to a shorter deadline.

2. In order to consider the matter, the Committee shall appoint one of its members to act as rapporteur. The Committee may also appoint individual experts to advise it on specific questions. When appointing experts, the Committee shall define their tasks and specify the time-limit for the completion of these tasks.

3. Before issuing its opinion, the Committee shall provide the applicant or the marketing authorisation holder with an opportunity to present written or oral explanations within a time limit which it shall specify. The opinion of the Committee shall be accompanied by a draft summary of product characteristics for the product and a draft text of the labelling and package leaflet. If necessary, the Committee may call upon any other person to provide information relating to the matter before it. The Committee may suspend the time-limits referred to in paragraph 1 in order to allow the applicant or the marketing authorisation holder to prepare explanations.

4. The Agency shall forthwith inform the applicant or the marketing authorisation holder where the opinion of the Committee is that:

(a) the application does not satisfy the criteria for authorisation; or

(b) the summary of the product characteristics proposed by the applicant or the marketing authorisation holder in accordance with Article 11 should be amended; or

(c) the authorisation should be granted subject to certain conditions, in view of conditions considered essential for the safe and effective use of the medicinal product including pharmacovigilance; or

(d) a marketing authorisation should be suspended, varied or revoked. Within 15 days after receipt of the opinion, the applicant or the marketing authorisation holder may notify the Agency in writing of his intention to request a re-examination of the opinion. In that case, he shall forward to the Agency the detailed grounds for the request within 60 days after receipt of the opinion. Within 60 days following receipt of the grounds for the request, the Committee shall re-examine its opinion in accordance with the fourth subparagraph of Article 62(1) of Regulation (EC) No $726 / 2004$. The reasons for the conclusion reached shall be annexed to the assessment report referred to in paragraph 5 of this Article. 5. Within 15 days after its adoption, the Agency shall forward the final opinion of the Committee to the Member States, to the Commission and to the applicant or the marketing authorisation holder, together with a report describing the assessment of the medicinal product and stating the reasons for its conclusions. 30.4.2004 EN Official Journal of the European Union L $136 / 45$ In the event of an opinion in favour of granting or maintaining an authorisation to place the medicinal product concerned on the market, the following documents shall be annexed to the opinion: 
(a) a draft summary of the product characteristics, as referred to in Article 11;

(b) any conditions affecting the authorisation within the meaning of paragraph 4(c);

(c) details of any recommended conditions or restrictions with regard to the safe and effective use of the medicinal product;

(d) the proposed text of the labelling and leaflet.' 27) Article 33 shall be amended as follows:

(a) in the first paragraph, '30 days' shall be replaced by ' 15 days';

(b) in the second paragraph, 'Article 32(5)(a) and (b)' shall be replaced by 'Article 32(5), second subparagraph';

(c) in the fourth paragraph, the words 'or the marketing authorisation holder' shall be added after the word 'applicant';

28) Article 34 shall be replaced by the following: 'Article 34

1. The Commission shall take a final decision in accordance with, and within 15 days after the end of, the procedure referred to in Article 121(3).

2. The rules of procedure of the Standing Committee established by Article 121(1) shall be adjusted to take account of the tasks incumbent upon it under this Chapter. Those adjustments shall entail the following provisions:

(a) except in cases referred to in the third paragraph of Article 33, the opinion of the Standing Committee shall be given in writing;

(b) Member States shall have 22 days to forward their written observations on the draft decision to the Commission. However, if a decision has to be taken urgently, a shorter time-limit may be set by the Chairman according to the degree of urgency involved. This time-limit shall not, otherwise than in exceptional circumstances, be shorter than 5 days;

(c) Member States shall have the option of submitting a written request that the draft Decision be discussed in a plenary meeting of the Standing Committee. Where, in the opinion of the Commission, the written observations of a Member State raise important new questions of a scientific or technical nature which have not been addressed in the opinion delivered by the Agency, the Chairman shall suspend the procedure and refer the application back to the Agency for further consideration. The provisions necessary for the implementation of this paragraph shall be adopted by the Commission in accordance with the procedure referred to in Article 121(2).

3. The decision as referred to in paragraph 1 shall be addressed to all Member States and reported for information to the marketing authorisation holder or applicant. The concerned Member States and the reference Member State shall either grant or revoke the marketing authorisation, or vary its terms as necessary to comply with the decision within 30 days following its notification, and they shall refer to it. They shall inform the Commission and the Agency accordingly.'; 29) the third subparagraph of Article 35(1) shall be deleted; 30) in Article 38, paragraph 2 shall be replaced by the following:

'2. At least every ten years the Commission shall publish a report on the experience acquired on the basis of the procedures described in this Chapter and shall propose any 
amendments which may be necessary to improve those procedures. The Commission shall submit this report to the European Parliament and to the Council.';

31) Article 39 shall be replaced by the following: 'Article 39 Article 29(4), (5) and (6) and Articles 30 to 34 shall not apply to the homeopathic medicinal products referred to in Article 14. Articles 28 to 34 shall not apply to the homeopathic medicinal products referred to in Article 16(2).';

32) the following paragraph shall be added to Article 40: '4. The Member States shall forward to the Agency a copy of the authorisation referred to in paragraph 1. The Agency shall enter that information on the Community database referred to in Article 111(6).'; L 136/46 EN Official Journal of the European Union 30.4.2004

33 ) in Article 46, point (f) shall be replaced by the following: '(f) to comply with the principles and guidelines of good manufacturing practice for medicinal products and to use as starting materials only active substances, which have been manufactured in accordance with the detailed guidelines on good manufacturing practice for starting materials. This point shall also be applicable to certain excipients, the list of which as well as the specific conditions of application shall be established by a Directive adopted by the Commission in accordance with the procedure referred to in Article 121(2).';

34) the following Article shall be inserted:

'Article $46 a$

1. For the purposes of this Directive, manufacture of active substances used as starting materials shall include both total and partial manufacture or import of an active substance used as a starting material as defined in Part I, point 3.2.1.1 (b) Annex I, and the various processes of dividing up, packaging or presentation prior to its incorporation into a medicinal product, including repackaging or re-labelling, such as are carried out by a distributor of starting materials.

2. Any amendments necessary to adapt paragraph 1 to new scientific and technical developments shall be laid down in accordance with the procedure referred to in Article 121(2).';

35) in Article 47, the following paragraphs shall be added: 'The principles of good manufacturing practice for active substances used as starting materials referred to in point (f) of Article 46 shall be adopted in the form of detailed guidelines. The Commission shall also publish guidelines on the form and content of the authorisation referred to in Article 40(1), on the reports referred to in Article 111(3) and on the form and content of the certificate of good manufacturing practice referred to in Article 111(5).';

36) in Article 49(1), 'minimum' shall be deleted;

37) in Article 49(2), fourth subparagraph, first indent 'Applied physics' shall be replaced by 'Experimental physics';

38) in Article 50(1), 'in the State concerned' shall be replaced by 'within the Community';

39) in Article 51(1), point (b) shall be replaced by the following: 
(b) in the case of medicinal products coming from third countries, irrespective of whether the product has been manufactured in the Community, that each production batch has undergone in a Member State a full qualitative analysis, a quantitative analysis of at least all the active substances and all the other tests or checks necessary to ensure the quality of medicinal products in accordance with the requirements of the marketing authorisation.';

40) Article 54 shall be amended as follows:

(a) point (a) shall be replaced by the following: '(a) the name of the medicinal product followed by its strength and pharmaceutical form, and, if appropriate, whether it is intended for babies, children or adults; where the product contains up to three active substances, the international non-proprietary name (INN) shall be included, or, if one does not exist, the common name;';

(b) in point (d), 'guidelines' shall be replaced by 'detailed guidance';

(c) Point (e) shall be replaced by the following: '(e) the method of administration and, if necessary, the route of administration. Space shall be provided for the prescribed dose to be indicated.';

(d) point (f) shall be replaced by the following: '(f) a special warning that the medicinal product must be stored out of the reach and sight of children;';

(e) Point (j) shall be replaced by the following:

'(j) specific precautions relating to the disposal of unused medicinal products or waste derived from medicinal products, where appropriate, as well as reference to any appropriate collection system in place;';

(f) point (k) shall be replaced by the following: '(k) the name and address of the marketing authorisation holder and, where applicable, the name of the representative appointed by the holder to represent him;';

(g) point (n) shall be replaced by the following: '(n) in the case of non-prescription medicinal products, instructions for use';

30.4.2004 EN Official Journal of the European Union L 136/47

41) Article 55 shall be amended as follows:

(a) in paragraph 1, 'in Articles 54 and 62' shall be replaced by 'in Article 54';

(b) the first indent of paragraph 2 shall be replaced by the following:

'- the name of the medicinal product as laid down in point (a) of Article 54,';

(c) the first indent of paragraph 3 shall be replaced by the following:

'- the name of the medicinal product as laid down in point (a) of Article 54 and, if necessary, the route of administration,';

42) the following Article shall be inserted:

'Article $56 a$

The name of the medicinal product, as referred to in Article 54, point (a) must also be expressed in Braille format on the packaging. The marketing authorisation holder shall ensure that the package information leaflet is made available on request from patients' organisations in formats appropriate for the blind and partially-sighted.' 43 ) in Article 57, the following paragraph shall be added: 'For medicinal products 
authorised under Regulation (EC) No 726/2004, Member States shall, when applying this Article, observe the detailed guidance referred to in Article 65 of this Directive.';

44) Article 59 shall be replaced by the following:

'Article 59

1. The package leaflet shall be drawn up in accordance with the summary of the product characteristics; it shall include, in the following order:

(a) for the identification of the medicinal product:

(i) the name of the medicinal product followed by its strength and pharmaceutical form, and, if appropriate, whether it is intended for babies, children or adults. The common name shall be included where the product contains only one active substance and if its name is an invented name;

(ii) the pharmaco-therapeutic group or type of activity in terms easily comprehensible for the patient;

(b) the therapeutic indications;

(c) a list of information which is necessary before the medicinal product is taken:

(i) contra-indications;

(ii) appropriate precautions for use;

(iii) forms of interaction with other medicinal products and other forms of interaction (e.g. alcohol, tobacco, foodstuffs) which may affect the action of the medicinal product;

(iv) special warnings;

(d) the necessary and usual instructions for proper use, and in particular:

(i) the dosage,

(ii) the method and, if necessary, route of administration;

(iii) the frequency of administration, specifying if necessary the appropriate time at which the medicinal product may or must be administered; and, as appropriate, depending on the nature of the product:

(iv) the duration of treatment, where it should be limited;

(v) the action to be taken in case of an overdose (such as symptoms, emergency procedures);

(vi) what to do when one or more doses have not been taken;

(vii) indication, if necessary, of the risk of withdrawal effects;

(viii) a specific recommendation to consult the doctor or the pharmacist, as appropriate, for any clarification on the use of the product;

(e) a description of the adverse reactions which may occur under normal use of the medicinal product and, if necessary, the action to be taken in such a case; the patient should be expressly asked to communicate any adverse reaction which is not mentioned in the package leaflet to his doctor or pharmacist; L 136/48 EN Official Journal of the European Union 30.4.2004

(f) a reference to the expiry date indicated on the label, with:

(i) a warning against using the product after that date;

(ii) where appropriate, special storage precautions;

(iii) if necessary, a warning concerning certain visible signs of deterioration; 
(iv) the full qualitative composition (in active substances and excipients) and the quantitative composition in active substances, using common names, for each presentation of the medicinal product;

(v) for each presentation of the product, the pharmaceutical form and content in weight, volume or units of dosage;

(vi) the name and address of the marketing authorisation holder and, where applicable, the name of his appointed representatives in the Member States;

(vii) the name and address of the manufacturer;

(g) where the medicinal product is authorised in accordance with Articles 28 to 39 under different names in the Member States concerned, a list of the names authorised in each Member State;

(h) the date on which the package leaflet was last revised. 2. The list set out in point (c) of paragraph 1 shall:

(a) take into account the particular condition of certain categories of users (children, pregnant or breastfeeding women, the elderly, persons with specific pathological conditions);

(b) mention, if appropriate, possible effects on the ability to drive vehicles or to operate machinery;

(c) list those excipients knowledge of which is important for the safe and effective use of the medicinal product and which are included in the detailed guidance published pursuant to Article 65.

3. The package leaflet shall reflect the results of consultations with target patient groups to ensure that it is legible, clear and easy to use.'; 45) Article 61(1) shall be replaced by the following:

'1. One or more mock-ups of the outer packaging and the immediate packaging of a medicinal product, together with the draft package leaflet, shall be submitted to the authorities competent for authorising marketing when the marketing authorisation is requested. The results of assessments carried out in cooperation with target patient groups shall also be provided to the competent authority.';

46) in Article 61(4), 'or as appropriate' shall be replaced by 'and';

47 ) in Article 62, 'for health education' shall be replaced by 'for the patient'; 48) Article 63 shall be amended as follows:

(a) the following subparagraph shall be added to paragraph 1: 'In the case of certain orphan medicinal products, the particulars listed in Article 54 may, on reasoned request, appear in only one of the official languages of the Community.';

(b) paragraphs 2 and 3 shall be replaced by the following:

' 2 . The package leaflet must be written and designed to be clear and understandable, enabling the users to act appropriately, when necessary with the help of health professionals. The package leaflet must be clearly legible in the official language or languages of the Member State in which the medicinal product is placed on the market. The first subparagraph shall not prevent the package leaflet from being printed in several languages, provided that the same information is given in all the languages used. 
3. When the product is not intended to be delivered directly to the patient, the competent authorities may grant an exemption to the obligation that certain particulars should appear on the labelling and in the package leaflet and that the leaflet must be in the official language or languages of the Member State in which the product is placed on the market.'; 49) Article 65 shall be replaced by the following:

\section{'Article 65}

In consultation with the Member States and the parties concerned, the Commission shall draw up and publish detailed guidance concerning in particular: 30.4.2004 EN Official Journal of the European Union L 136/49

(a) the wording of certain special warnings for certain categories of medicinal products;

(b) the particular information needs relating to non-prescription medicinal products;

(c) the legibility of particulars on the labelling and package leaflet;

(d) the methods for the identification and authentication of medicinal products;

(e) the list of excipients which must feature on the labelling of medicinal products and the way in which these excipients must be indicated;

(f) harmonised provisions for the implementation of Article 57.';

50) Article 66(3), fourth indent shall be replaced by:

'- the name and address of the manufacturer,';

51) Article 69(1) shall be amended as follows:

(a) the first indent shall be replaced by the following:

- the scientific name of the stock or stocks followed by the degree of dilution, making use of the symbols of the pharmacopoeia used in accordance with Article 1(5); if the homeopathic medicinal product is composed of two or more stocks, the scientific names of the stocks on the labelling may be supplemented by an invented name';

(b) the last indent shall be replaced by the following:

'- a warning advising the user to consult a doctor if the symptoms persist';

52) Article 70(2) shall be amended as follows:

(a) point (a) shall be replaced by the following: '(a) medicinal products on medical prescription for renewable or non-renewable delivery;';

(b) point (c) shall be replaced by the following: '(c) medicinal products on "restricted" medical prescription, reserved for use in certain specialised areas.';

53) Article 74 shall be replaced by the following:

'Article 74

When new facts are brought to their attention, the competent authorities shall examine and, as appropriate, amend the classification of a medicinal product by applying the criteria listed in Article 71.';

54) the following Article shall be inserted:

'Article $74 a$

Where a change of classification of a medicinal product has been authorised on the basis of significant pre-clinical tests or clinical trials, the competent authority shall not 
refer to the results of those tests or trials when examining an application by another applicant for or holder of marketing authorisation for a change of classification of the same substance for one year after the initial change was authorised.';

55) Article 76 shall be amended as follows:

(a) the existing text shall become paragraph 1 ;

(b) the following paragraphs shall be added:

' 2 . In the case of wholesale distribution and storage, medicinal products shall be covered by a marketing authorisation granted pursuant to Regulation (EC) No $726 / 2004$ or by the competent authorities of a Member State in accordance with this Directive.

3. Any distributor, not being the marketing authorisation holder, who imports a product from another Member State shall notify the marketing authorisation holder and the competent authority in the Member State to which the product will be imported of his intention to import it. In the case of products which have not been granted an authorisation pursuant to Regulation (EC) No 726/2004, the notification to the competent authority shall be without prejudice to additional procedures provided for in the legislation of that Member State.';

56) the second indent of point (e) of Article 80 shall be replaced by the following:

'- name of the medicinal product,';

57) Article 81 shall be replaced by the following:

'Article 81

With regard to the supply of medicinal products to pharmacists and persons authorised or entitled to supply medicinal products to the public, Member States shall not impose upon the holder of a distribution authorisation which has been granted by another Member State any obligation, in particular public service obligations, more stringent than those they impose on persons whom they have themselves authorised to engage in equivalent activities. L $136 / 50$ EN Official Journal of the European Union 30.4.2004 The holder of a marketing authorisation for a medicinal product and the distributors of the said medicinal product actually placed on the market in a Member State shall, within the limits of their responsibilities, ensure appropriate and continued supplies of that medicinal product to pharmacies and persons authorised to supply medicinal products so that the needs of patients in the Member State in question are covered. The arrangements for implementing this Article should, moreover, be justified on grounds of public health protection and be proportionate in relation to the objective of such protection, in compliance with the Treaty rules, particularly those concerning the free movement of goods and competition.';

58 ) in Article 82, the second indent of the first paragraph shall be replaced by the following:

'- the name and pharmaceutical form of the medicinal product,';

59) Article 84 shall be replaced by the following:

'Article 84

The Commission shall publish guidelines on good distribution practice. To this end, it shall consult the Committee for Medicinal Products for Human Use and the Pharmaceutical Committee established by Council Decision 75/320/EEC (*). 
60) Article 85 shall be replaced by the following:

'Article 85

This Title shall apply to homeopathic medicinal products.';

61) the fourth indent of Article 86(2) shall be replaced by the following:

'- information relating to human health or diseases, provided that there is no reference, even indirect, to medicinal products';

62) Article 88 shall be replaced by the following:

'Article 88

1. Member States shall prohibit the advertising to the general public of medicinal products which:

(a) are available on medical prescription only, in accordance with Title VI;

(b) contain substances defined as psychotropic or narcotic by international convention, such as the United Nations Conventions of 1961 and 1971.

2. Medicinal products may be advertised to the general public which, by virtue of their composition and purpose, are intended and designed for use without the intervention of a medical practitioner for diagnostic purposes or for the prescription or monitoring of treatment, with the advice of the pharmacist, if necessary.

3. Member States shall be entitled to ban, on their territory, advertising to the general public of medicinal products the cost of which may be reimbursed.

4. The prohibition contained in paragraph 1 shall not apply to vaccination campaigns carried out by the industry and approved by the competent authorities of the Member States.

5. The prohibition referred to in paragraph 1 shall apply without prejudice to Article 14 of Directive 89/552/EEC.

6. Member States shall prohibit the direct distribution of medicinal products to the public by the industry for promotional purposes.';

63) the following text is inserted after Article 88:

\section{'TITLE VIIIa}

\section{INFORMATION AND ADVERTISING}

\section{Article $88 a$}

Within three years of the entry into force of Directive 2004/726/EC, the Commission shall, following consultations with patients' and consumers' organisations, doctors' and pharmacists' organisations, Member States and other interested parties, present to the European Parliament and the Council a report on current practice with regard to information provision - particularly on the Internet - and its risks and benefits for patients. Following analysis of the above data, the Commission shall, if appropriate, put forward proposals setting out an information strategy to ensure good-quality, objective, reliable and non-promotional information on medicinal products and other treatments and shall address the question of the information source's liability.'; 64) Article 89 shall be amended as follows:

(a) the first indent of point (b) of paragraph 1 shall be replaced by the following:

(*) OJ L 147, 9.6.1975, p. 23.'; 
(does not affect the English version);

30.4.2004 EN Official Journal of the European Union L 136/51

(b) paragraph 2 shall be replaced by the following:

'2. Member States may decide that the advertising of a medicinal product to the general public may, notwithstanding paragraph 1 , include only the name of the medicinal product or its international non-proprietary name, where this exists, or the trademark if it is intended solely as a reminder.'; 65) in Article 90, point (1) shall be deleted; 66) in Article 91, paragraph 2 shall be replaced by the following:

'2. Member States may decide that the advertising of a medicinal product to persons qualified to prescribe or supply such products may, notwithstanding paragraph 1 , include only the name of the medicinal product, or its international non-proprietary name, where this exists, or the trademark, if it is intended solely as a reminder.'; 67) Article 94(2) shall be replaced by the following:

'2. Hospitality at sales promotion events shall always be strictly limited to their main purpose and must not be extended to persons other than health-care professionals.'; 68) Article 95 shall be replaced by the following:

\section{'Article 95}

The provisions of Article 94(1) shall not prevent hospitality being offered, directly or indirectly, at events for purely professional and scientific purposes; such hospitality shall always be strictly limited to the main scientific objective of the event; it must not be extended to persons other than health-care professionals.';

69) point (d) of Article 96(1) shall be replaced by the following:

'(d) each sample shall be no larger than the smallest presentation on the market;';

70) in Article 98, the following paragraph shall be added:

'3. The Member States shall not prohibit the co-promotion of a medicinal product by the holder of the marketing authorisation and one or more companies nominated by him.';

71) Article 100 shall be replaced by the following:

'Article 100

Advertising of the homeopathic medicinal products referred to in Article 14(1) shall be subject to the provisions of this Title with the exception of Article 87(1). However, only the information specified in Article 69(1) may be used in the advertising of such medicinal products.';

72) in Article 101, the second paragraph shall be replaced by the following:

'The Member States may impose specific requirements on doctors and other healthcare professionals in respect of the reporting of suspected serious or unexpected adverse reactions.';

73) Article 102 shall be replaced by the following:

'Article 102

In order to ensure the adoption of appropriate and harmonised regulatory decisions concerning the medicinal products authorised within the Community, having regard to information obtained about adverse reactions to medicinal products under normal conditions of use, the Member States shall operate a pharmacovigilance system. This 
system shall be used to collect information useful in the surveillance of medicinal products, with particular reference to adverse reactions in human beings, and to evaluate such information scientifically. Member States shall ensure that suitable information collected within this system is communicated to the other Member States and the Agency. The information shall be recorded in the database referred to in point (1) of the second subparagraph of Article 57(1) of Regulation (EC) No $726 / 2004$ and shall be permanently accessible to all Member States and without delay to the public. This system shall also take into account any available information on misuse and abuse of medicinal products which may have an impact on the evaluation of their benefits and risks.';

74) the following Article shall be inserted:

'Article $102 a$

The management of funds intended for activities connected with pharmacovigilance, the operation of communication networks and market surveillance shall be under the permanent control of the competent authorities in order to guarantee their independence.';

L 136/52 EN Official Journal of the European Union 30.4.2004

75 ) in Article 103, the introductory phrase of the second paragraph shall be replaced by the following: 'That qualified person shall reside in the Community and shall be responsible for the following:';

76) Articles 104 to 107 shall be replaced by the following:

'Article 104

1. The marketing authorisation holder shall be required to maintain detailed records of all suspected adverse reactions occurring either in the Community or in a third country. Save in exceptional circumstances, these reactions shall be communicated electronically in the form of a report in accordance with the guidelines referred to in Article 106(1).

2. The marketing authorisation holder shall be required to record all suspected serious adverse reactions which are brought to his attention by a health-care professional and to report them promptly to the competent authority of the Member State on whose territory the incident occurred, and no later than 15 days following the receipt of the information.

3. The marketing authorisation holder shall be required to record and report all other suspected serious adverse reactions which meet the notification criteria in accordance with the guidelines referred to in Article 106(1), of which he can reasonably be expected to have knowledge, promptly to the competent authority of the Member State in whose territory the incident occurred, and no later than 15 days following the receipt of the information.

4. The marketing authorisation holder shall ensure that all suspected serious unexpected adverse reactions and any suspected transmission via a medicinal product of any infectious agent occurring in the territory of a third country are reported promptly in accordance with the guidelines referred to in Article 106(1), so that the Agency and the competent authorities of the Member States in which the medicinal 
product is authorised are informed of them, and no later than 15 days following the receipt of the information.

5. By way of derogation from paragraphs 2,3 and 4 , in the case of medicinal products which are covered by Directive $87 / 22 /$ EEC or which have qualified for the procedures laid down in Articles 28 and 29 of this Directive or which have been the subject of the procedures under Articles 32, 33 and 34 of this Directive, the marketing authorisation holder shall also ensure that all suspected serious adverse reactions occurring in the Community are reported in such a way as to be accessible to the reference Member State or to any competent authority acting as reference Member State. The reference Member State shall assume the responsibility of analysing and monitoring such adverse reactions.

6. Unless other requirements have been laid down as a condition for the granting of the marketing authorisation, or subsequently as indicated in the guidelines referred to in Article 106(1), reports of all adverse reactions shall be submitted to the competent authorities in the form of a periodic safety update report, immediately upon request or at least every six months after authorisation and until the placing on the market. Periodic safety update reports shall also be submitted immediately upon request or at least every six months during the first two years following the initial placing on the market and once a year for the following two years. Thereafter, the reports shall be submitted at three-yearly intervals, or immediately upon request. The periodic safety update reports shall include a scientific evaluation of the risk-benefit balance of the medicinal product.

7. The Commission may lay down provisions to amend paragraph 6 in view of experience gained through its operation. The Commission shall adopt the provisions in accordance with the procedure referred to in Article 121(2).

8. Following the granting of a marketing authorisation, the marketing authorisation holder may request the amendment of the periods referred to in paragraph 6 in accordance with the procedure laid down by Commission Regulation (EC) No $1084 / 2003(*)$.

9. The holder of a marketing authorisation may not communicate information relating to pharmacovigilance concerns to the general public in relation to its authorised medicinal product without giving prior or simultaneous notification to the competent authority. In any case, the marketing authorisation holder shall ensure that such information is presented objectively and is not misleading. Member States shall take the necessary measures to ensure that a marketing authorisation holder who fails to discharge these obligations is subject to effective, proportionate and dissuasive penalties.

Article 105

1. The Agency, in collaboration with the Member States and the Commission, shall set up a data-processing network to facilitate the exchange of pharmacovigilance information regarding medicinal products marketed in the Community in order to allow all competent authorities to share the information at the same time. 30.4.2004 EN Official Journal of the European Union L 136/53 
2. Making use of the network referred to in paragraph 1, Member States shall ensure that reports of suspected serious adverse reactions that have taken place on their territory are promptly made available to the Agency and the other Member States, and in any case within 15 days after their notification at the latest.

3. The Member States shall ensure that reports of suspected serious adverse reactions that have taken place on their territory are promptly made available to the marketing authorisation holder, and in any case within 15 days after their notification at the latest.

\section{Article 106}

1. In order to facilitate the exchange of information on pharmacovigilance within the Community, the Commission, after consulting the Agency, the Member States and interested parties, shall draw up guidelines on the collection, verification and presentation of adverse reaction reports, including technical requirements for electronic exchange of pharmacovigilance information in accordance with internationally agreed formats, and shall publish a reference to an internationally agreed medical terminology. Acting in accordance with the guidelines, marketing authorisation holders shall use internationally agreed medical terminology for the reporting of adverse reactions. These guidelines shall be published in Volume 9 of The Rules governing Medicinal Products in the European Community and shall take account of international harmonisation work carried out in the field of pharmacovigilance.

2. For the interpretation of the definitions referred to in points (11) to (16) of Article 1 and of the principles outlined in this Title, the marketing authorisation holder and the competent authorities shall follow the guidelines referred to in paragraph 1 .

Article 107

1. Where, as a result of the evaluation of pharmacovigilance data, a Member State considers that a marketing authorisation should be suspended, revoked or varied in accordance with the guidelines referred to in Article 106(1), it shall forthwith inform the Agency, the other Member States and the marketing authorisation holder.

2. Where urgent action to protect public health is necessary, the Member State concerned may suspend the marketing authorisation of a medicinal product, provided that the Agency, the Commission and the other Member States are informed no later than the following working day. When the Agency is informed in accordance with paragraph 1 in relation to suspensions and revocation, or the first subparagraph of this paragraph, the Committee shall prepare an opinion within a time-frame to be determined depending on the urgency of the matter. In relation to variations, the Committee may upon request from a Member State prepare an opinion. Acting on the basis of this opinion, the Commission may request all Member States in which the product is being marketed to take temporary measures immediately. The final measures shall be adopted in accordance with the procedure referred to in Article 121(3).

77) Article 111 shall be amended as follows:

(*) OJ L 159, 27.6.2003, p. 1.'; 
(a) paragraph 1 shall be replaced by the following:

'1. The competent authority of the Member State concerned shall ensure, by means of repeated inspections, and if necessary unannounced inspections, and, where appropriate, by asking an Official Medicines Control Laboratory or a laboratory designated for that purpose to carry out tests on samples, that the legal requirements governing medicinal products are complied with. The competent authority may also carry out unannounced inspections at the premises of manufacturers of active substances used as starting materials, or at the premises of marketing authorisation holders whenever it considers that there are grounds for suspecting non-compliance with the principles and guidelines of good manufacturing practice referred to in Article 47. These inspections may also be carried out at the request of a Member State, the Commission or the Agency. In order to verify whether the data submitted in order to obtain a conformity certificate comply with the monographs of the European Pharmacopoeia, the standardisation body of the nomenclatures and the quality norms within the meaning of the Convention relating to the elaboration of the European Pharmacopoeia $*^{*}$ ) (European Directorate for the quality of Medicinal Products) may ask the Commission or the Agency to request such an inspection when the starting material concerned is the subject of a European Pharmacopoeia monograph. The competent authority of the Member State concerned may carry out inspections of starting material manufacturers at the specific request of the manufacturer himself. L 136/54 EN Official Journal of the European Union 30.4.2004 Such inspections shall be carried out by officials representing the competent authority who shall be empowered to:

(a) inspect the manufacturing or commercial establishments of manufacturers of medicinal products or of active substances used as starting materials, and any laboratories employed by the holder of the manufacturing authorisation to carry out checks pursuant to Article 20;

(b) take samples including with a view to independent tests being carried out by an Official Medicines Control Laboratory or a laboratory designated for that purpose by a Member State;

(c) examine any documents relating to the object of the inspection, subject to the provisions in force in the Member States on 21 May 1975 placing restrictions on these powers with regard to the description of the manufacturing method;

(d) inspect the premises, records and documents of marketing authorisation holders or any firms employed by the marketing authorisation holder to perform the activities described in Title IX, and in particular Articles 103 and 104.

(b) paragraph 3 shall be replaced by the following: ' 3 . After every inspection as referred to in paragraph 1 , the officials representing the competent authority shall report on whether the manufacturer complies with the principles and guidelines of good manufacturing practice laid down in Article 47 or, where appropriate, with the requirements laid down in Articles 101 to 108. The content of such reports shall be

(*) OJ L 158, 25.6.1994, p. 19.'; 
communicated to the manufacturer or marketing authorisation holder who has undergone the inspection.';

(c) the following paragraphs shall be added:

'4. Without prejudice to any arrangements which may have been concluded between the Community and third countries, a Member State, the Commission or the Agency may require a manufacturer established in a third country to submit to an inspection as referred to in paragraph 1.

5. Within 90 days of an inspection as referred to in paragraph 1, a certificate of good manufacturing practice shall be issued to a manufacturer if the outcome of the inspection shows that the manufacturer complies with the principles and guidelines of good manufacturing practice as provided for by Community legislation. If inspections are performed as part of the certification procedure for the monographs of the European Pharmacopoeia, a certificate shall be drawn up.

6. Member States shall enter the certificates of good manufacturing practice which they issue in a Community database managed by the Agency on behalf of the Community.

7. If the outcome of the inspection as referred to in paragraph 1 is that the manufacturer does not comply with the principles and guidelines of good manufacturing practice as provided for by Community legislation, the information shall be entered in the Community database as referred to in paragraph 6.';

78 ) in Article 114(1) and (2), the terms 'by a State laboratory or a laboratory designated for that purpose' shall be replaced by the terms 'by an Official Medicines Control Laboratory or a laboratory that a Member State has designated for that purpose';

79) Article 116 shall be replaced by the following:

'Article 116

The competent authorities shall suspend, revoke, withdraw or vary a marketing authorisation if the view is taken that the product is harmful under normal conditions of use, or that it lacks therapeutic efficacy, or that the risk-benefit balance is not positive under the normal conditions of use, or that its qualitative and quantitative composition is not as declared. Therapeutic efficacy is lacking when it is concluded that therapeutic results cannot be obtained from the medicinal product. An authorisation shall also be suspended, revoked, withdrawn or varied where the particulars supporting the application as provided for in Article 8 or Articles 10, 10a, 10b, 10c and 11 are incorrect or have not been amended in accordance with Article 23, or where the controls referred to in Article 112 have not been carried out.';

80) Article 117(1) shall be replaced by the following: ' 1 . Without prejudice to the measures provided for in Article 116, Member States shall take all appropriate steps to ensure that the supply of the medicinal product is prohibited and the medicinal product withdrawn from the market, if the view is taken that:

(a) the medicinal product is harmful under normal conditions of use; or

(b) it lacks therapeutic efficacy; or 30.4.2004 EN Official Journal of the European Union L 136/55 
(c) the risk-benefit balance is not favourable under the authorised conditions of use; or

(d) its qualitative and quantitative composition is not as declared; or

(e) the controls on the medicinal product and/or on the ingredients and the controls at an intermediate stage of the manufacturing process have not been carried out or if some other requirement or obligation relating to the grant of the manufacturing authorisation has not been fulfilled.';

81) Article 119 shall be replaced by the following:

'Article 119

The provisions of this Title shall apply to homeopathic medicinal products.';

82) Articles 121 and 122 shall be replaced by the following:

'Article 121

1. The Commission shall be assisted by the Standing Committee on Medicinal Products for Human Use, hereinafter called "the Standing Committee", in the task of adapting to technical progress the directives on the removal of technical barriers to trade in the medicinal products sector.

2. Where reference is made to this paragraph, Articles 5 and 7 of Decision 1999/468/EC shall apply, having regard to the provisions of Article 8 thereof. The period laid down in Article 5(6) of Decision 1999/468/EC shall be set at three months.

3. Where reference is made to this paragraph, Articles 4 and 7 of Decision 1999/468/EC shall apply, having regard to the provisions of Article 8 thereof. The period laid down in Article 4(3) of Decision 1999/468/EC shall be set at one month.

4. The Standing Committee shall adopt its own rules of procedure which shall be made public.

\section{Article 122}

1. Member States shall take all appropriate measures to ensure that the competent authorities concerned communicate to each other such information as is appropriate to guarantee that the requirements placed on the authorisations referred to in Articles 40 and 77, on the certificates referred to in Article 111(5) or on the marketing authorisations are fulfilled.

2. Upon reasoned request, Member States shall forthwith communicate the reports referred to in Article 111(3) to the competent authorities of another Member State.

3. The conclusions reached in accordance with Article 111(1) shall be valid throughout the Community. However, in exceptional cases, if a Member State is unable, for reasons relating to public health, to accept the conclusions reached following an inspection under Article 111(1), that Member State shall forthwith inform the Commission and the Agency. The Agency shall inform the Member States concerned. When the Commission is informed of these divergences of opinion, it may, after consulting the Member States concerned, ask the inspector who performed the original inspection to perform a new inspection; the inspector may be accompanied by two other inspectors from Member States which are not parties to the disagreement.';

83 ) in Article 125, the third subparagraph shall be replaced by the following: 
'Decisions to grant or revoke a marketing authorisation shall be made publicly available.';

84) the following Article shall be inserted:

'Article $126 a$

1. In the absence of a marketing authorisation or of a pending application for a medicinal product authorised in another Member State in accordance with this Directive, a Member State may for justified public health reasons authorise the placing on the market of the said medicinal product.

2. When a Member State avails itself of this possibility, it shall adopt the necessary measures in order to ensure that the requirements of this Directive are complied with, in particular those referred to in Titles V, VI, VIII, IX and XI.

3. Before granting such an authorisation a Member State shall:

(a) notify the marketing authorisation holder, in the Member State in which the medicinal product concerned is authorised, of the proposal to grant an authorisation under this Article in respect of the product concerned; and

(b) request the competent authority in that State to furnish a copy of the assessment report referred to in Article 21(4) and of the marketing authorisation in force in respect of the said medicinal product. L 136/56 EN Official Journal of the European Union 30.4.2004

4. The Commission shall set up a publicly accessible register of medicinal products authorised under paragraph 1. Member States shall notify the Commission if any medicinal product is authorised, or ceases to be authorised, under paragraph 1, including the name or corporate name and permanent address of the authorisation holder. The Commission shall amend the register of medicinal products accordingly and make this register available on their website.

5. No later than 30 April 2008, the Commission shall present a report to the European Parliament and the Council concerning the application of this provision with a view to proposing any necessary amendments.';

$85)$ the following Article $126 \mathrm{~b}$ is inserted:

'Article $126 \mathrm{~b}$

In order to guarantee independence and transparency, the Member States shall ensure that members of staff of the competent authority responsible for granting authorisations, rapporteurs and experts concerned with the authorisation and surveillance of medicinal products have no financial or other interests in the pharmaceutical industry which could affect their impartiality. These persons shall make an annual declaration of their financial interests. In addition, the Member States shall ensure that the competent authority makes publicly accessible its rules of procedure and those of its committees, agendas for its meetings and records of its meetings, accompanied by decisions taken, details of votes and explanations of votes, including minority opinions.';

86) the following Article shall be inserted:

'Article $127 a$ 
When a medicinal product is to be authorised in accordance with Regulation (EC) No 726/2004 and the Scientific Committee in its opinion refers to recommended conditions or restrictions with regard to the safe and effective use of the medicinal product as provided for in Article 9(4)(c) of that Regulation, a decision addressed to the Member States shall be adopted in accordance with the procedure provided for in Articles 33 and 34 of this Directive, for the implementation of those conditions or restrictions.';

87) the following Article shall be inserted:

'Article $127 b$

Member States shall ensure that appropriate collection systems are in place for medicinal products that are unused or have expired.'

Article 2

The periods of protection provided for in Article 1, point 8, which amends Article 10(1) of Directive 2001/83/EC, shall not apply to reference medicinal products for which an application for authorisation has been submitted before the date of transposition referred to in Article 3 first paragraph.

Article 3

Member States shall bring into force the laws, regulations and administrative provisions necessary to comply with this Directive no later than 30 October 2005. They shall immediately inform the Commission thereof. When Member States adopt these measures, they shall contain a reference to this Directive or shall be accompanied by such a reference on the occasion of their official publication. The methods of making such reference shall be laid down by the Member States.

Article 4

This Directive shall enter into force on the day of its publication in the Official Journal of the European Union.

Article 5

This Directive is addressed to the Member States. Done at Strasbourg, 31 March 2004.

For the European Parliament

The President

P. COX

For the Council

The President

D. ROCHE

30.4.2004 EN Official Journal of the European Union L 136/57 